JurnalKeperawatanSilampari

Volume4,Nomor2,Juni2021

e-ISSN:2581-1975

p-ISSN:2597-7482

DOI: https://doi.org/10.31539/jks.v4i2.1924

DMEKpe

\title{
PENINGKATAN KEMAMPUAN PERAWAT DALAM INTERPRETASI EKG NORMAL DAN ARITMIA DENGAN METODE ANGKA "3"
}

\author{
Ii Ismail ${ }^{1}$, Dewi Purnamawati ${ }^{2}$, Wati Jumaiyah ${ }^{3}$, Fitrian Rayasari ${ }^{4}$ \\ Universitas Muhammadiyah Jakarta ${ }^{1,2,3,4}$ \\ iiismailpjnhk1978@gmail.com ${ }^{1}$
}

\begin{abstract}
ABSTRAK
Penelitian ini bertujuan untuk mengetahui pengaruh metode angka 3 terhadap kemampuan perawat dalam interpretasi EKG normal dan aritmia. Metode penelitian menggunakan desain quasi experiment one group pre-test and post-test with control group. Hasil penelitian terdapat perbedaan yang signifikan rata-rata nilai perawat dalam interpretasi EKG normal dan aritmia baik pada kelompok intervensi maupun kontrol (nilai p 0,007 dan 0,002). Uji regresi linier ganda menunjukkan variabel perlakuan memberikan kontribusi terhadap kemampuan perawat dalam intepretasi EKG normal dan aritmia dengan nilai $\mathrm{p}$ 0,002 dengan pola linier negative (Kemampuan perawat $=66,099-9,156$ (Perlakuan). Simpulan, terdapat perbedaan yang signifikan rata-rata nilai perawat dalam interpretasi EKG normal dan aritmia baik pada kelompok intervensi maupun kontrol. Namun kelompok intervensi dengan metode angka 3, memiliki selisih nilai rata-rata lebih besar dari kelompok kontrol. Secara statistik semakin banyak perlakuan penelitian maka kemampuan perawat dalam interpretasi EKG normal dan aritmia akan semakin menurun.
\end{abstract}

Kata Kunci : Aritmia, EKG Normal, Interpretasi EKG, Metode Angka 3

\section{ABSTRACT}

This study aims to determine the effect of the number 3 method on nurses' ability to interpret normal ECG and arrhythmias. The research method used a quasiexperimental design with one group pre-test and a post-test with a control group. The results showed that there was a significant difference in the mean score of nurses in the interpretation of normal ECG and arrhythmias in both the intervention and control groups (p-value 0.007 and 0.002). The multiple linear regression test showed that the treatment variable contributed to the nurse's ability to interpret normal ECG and arrhythmias with a p-value of 0.002 with a negative linear pattern (Nurses' ability = 66.099 - 9.156 (treatment). In conclusion, there is a significant difference in the average score of nurses in interpretation. Normal ECG and arrhythmia in both the intervention and control groups. However, the intervention group with the number 3 method had a greater difference in mean values than the control group. Statistically, the more research treatments, the nurses' ability to interpret normal ECG and arrhythmias would decrease.

Keywords: Arrhythmia, Normal EKG, Interpretation of ECG, Number Method 3 


\section{PENDAHULUAN}

Keterampilan dalam menginterpretasi EKG sangat dibutuhkan untuk seorang perawat terutama di emergensi, karena perawat adalah profesional kesehatan pertama yang menilai pasien dan melakukan perekaman EKG termasuk interpretasinya (McGrath \& Sampson, 2018).

Kemampuan perawat dalam melakukan interpretasi EKG belum optimal, kemampuan hanya sebatas melakukan perekaman dan dalam interpretasi masih sangat minimal. pendapat ini didukung oleh (Sila, 2018). Ini sesuai dengan hasil penelitian Marlisa \& Pratiwi (2019) didapatkan mayoritas pengetahuan perawat dalam interpretasi EKG adalah cukup dan berdasarkan observasi mayoritas pengetahuan perawat adalah kurang.

Mengingat pentingnya interpretasi EKG maka perawat dituntut untuk meningkatkan kemampuan dalam interpretasi EKG, untuk itu diperlukan sebuah metode baru agar perawat dapat dengan mudah melakukan interpretasi EKG. Salah satu metode dalam pembelajaran EKG adalah metode CRISP (Cardiac Rhythm Identification for Simple People)dimana dalam metode ini dibuat algoritma dalam memahami gambaran EKG dengan menggunakan 3 langkah, yang pertama mengidentifikasi komplek QRS, kedua mengidentifikasi gelombang $\mathrm{P}$ dan yang ketiga mengidentifikasi kembali komplek QRS apakah sempit atau lebar.

Penelitian yang dilakukan wibawa dengan membandingkan metode CRISP dengan modified DISBI didapatkan hasil penelitian menunjukkan bahwa terdapat perbedaan yang bermakna rerata nilai kemampuan interpretasi EKG strip sebelum dan sesudah dilakukan intervensi pada kelompok modified DISBI maupun CRISP dengan nilai $\mathrm{p}<0,001$ untuk kedua kelompok. Tidak terdapat perbedaan pengaruh metode belajar modified DISBI dan CRISP terhadap kemampuan perawat melakukan interpretasi EKG strip dengan $\mathrm{p}=0,996$ (IK95\%). Sehingga dapat disimpulkan metode CRISP dan modified DISBI terbukti sama-sama efektif dalam meningkatkan kemampuan perawat dalam melakukan interpretasi EKG strip (Wibawa, 2019). Sama halnya dengan penelitian yang dilakukan oleh Isık et al., (2020) menyatakan bahwa metode CRISP adalah metode yang efektif, sederhana dan mudah untuk perawat dalam interpretasi EKG terutama EKG yang mengancam jiwa.

Beberapa penelitian sebelumnya sudah pernah dilakukan menggunakan metode yang berbeda seperti metode CRISP, namun pada penelitian ini menggunakan metode angka 3 . Metode angka 3 yaitu sebuah metode yang didesain oleh peneliti agar pembelajaran lebih aktif, inovatif, kreatif dan menyenangkan, dengan pendekatan angka 3.

\section{METODE PENELITIAN}

Penelitian dilaksanakan pada tanggal 22 juli 2020 di RS Tarakan Jakarta, kedua kelompok mendapatkan perlakuan berupa workshop interpretasi EKG secara virtual dengan menggunakan aplikasi zoom meeting, kelompok intervensi diberikan dengan metode angka 3 sedangkan kelompok kontrol dengan modul INKAVIN.

Penelitian ini menggunakan desain quasi experiment one group pre-test and posttest with control group.Dengan jumlah sampel pada kelompok intervensi 58 responden sedangkan pada kelompok kontrol 53 responden yang dipilih secara random. Data dikumpulkan dengan menggunakan kuesioner yang diberikan dengan menggunakan google form. Selanjutnya data dianalisis secara multivariat dengan regresi liner ganda. 
HASIL PENELITIAN

Analisa univariat

Tabel. 1

Usia Responden Kelompok Intervensi dan Kelompok Kontrol Juli $2020(n=111)$

\begin{tabular}{lcccc}
\hline & Variabel & $\mathrm{n}$ & Mean & Standar Deviasi \\
\hline Intervensi & 58 & 34,16 & 6,912 \\
Kontrol & 53 & 31,96 & 6,569 \\
\hline
\end{tabular}

Berdasarkan tabel 1 menujukkan rerata usia kelompok intervensi 34,16 tahun sedangkan rerata kelompok kontrol 31,96 tahun (95\% CI).

\section{Tabel. 2}

Pendidikan, Pelatihan, Tempat Kerja dan Lama Kerja Responden Kelompok Intervensi dan Kelompok Kontrol Juli $2020(n=111)$

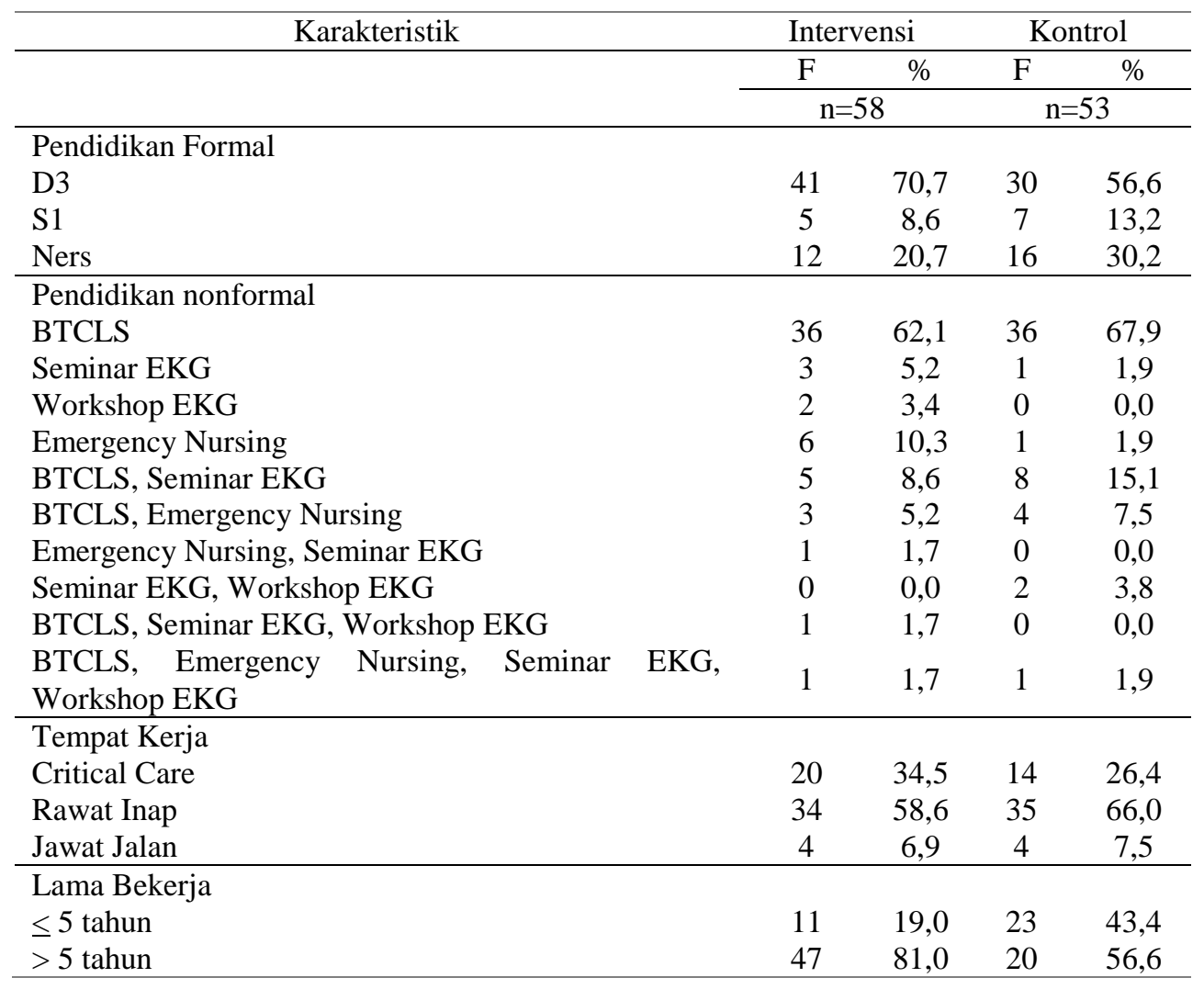

Berdasarkan tabel 2 menunjukan bahwa dari 58 responden kelompok intervensi, lebih dari separuh responden berpendidikan D3 Keperawatan(70,7\%), sebagian besar sudah mengikuti pendidikan non formal (100\%), lebih dari separuh responden berasal dari rawat inap $(58,6 \%)$, dan sebagian besar memiliki masa kerja $>5$ tahun $(80 \%)$. Sedangkan dari 53 responden pada kelompok kontrol, lebih dari separuh responden berpendidikan D3 Keperawatan (56,6\%), sebagian besar sudah mengikuti pendidikan non formal $(100 \%)$, lebih dari separuh responden berasal dari rawat inap $(66,0 \%)$ dan lebih dari separuh responden memiliki masa kerja $>5$ tahun $(56,6 \%)$. 


\section{Analisa Bivariat}

Tabel. 3

Hasil Uji Paired Samples T Test Interpretasi EKG Normal dan Aritmia Sebelum dan Sesudah Diberikan Perlakuan Intervensi dan Kontrol Juli $2020(n=111)$

\begin{tabular}{lcccc}
\hline \multicolumn{1}{c}{ Perlakuan } & N & Mean & SD & p-value \\
\hline Intervensi & & & & \\
\hline Pre Test & \multirow{2}{*}{58} & 34,25 & 11,48 & \multirow{2}{*}{0,007} \\
Post Test & & 56,94 & 15,71 & \\
\hline Kontrol & \multirow{2}{*}{53} & 33,92 & 8,296 & \multirow{2}{*}{0,002} \\
\hline Pre Test & & 47,78 & 13,91 & \\
Post Test & & & & \\
\hline
\end{tabular}

Berdasarkan tabel 3 menunjukkan perbedaan rerata nilai kelompok intervensi lebih besar dari kelompok kontrol. Terdapat perbedaan signifikan rerata nilai kemampuan perawat dalam intepretasi EKG normal dan aritmia sebelum dan sesuah perlakuan baik pada kelompok intervensi maupun kelompok kontrol ( $p$-value 0,007 dan 0,002). Namun kelompok intervensi memiliki selisih nilai rerata lebih besar dari kelompok kontrol.

Tabel. 4

Hubungan Variabel Karakteristik Responden terhadap Kemampuan Interpretasi EKG Normal dan Aritmia Juli $2020(n=111)$

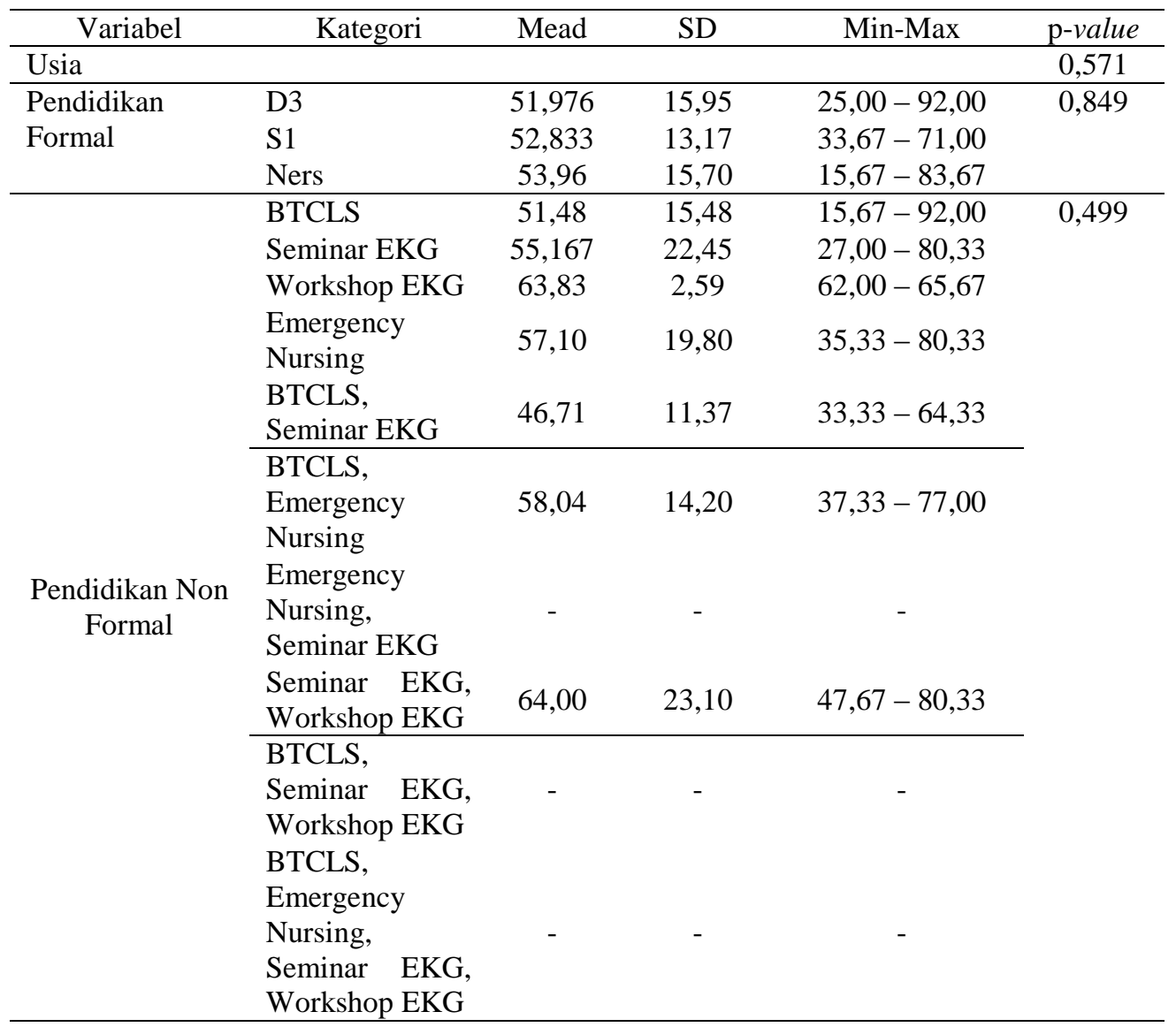




\begin{tabular}{llcccc}
\hline Tempat Kerja & Critical Care & 57,62 & 15,97 & $27,33-92,00$ & 0,073 \\
& Rawat Inap & 50,25 & 15,41 & $15,67-87,00$ & \\
& Jawat Jalan & 51,13 & 9,45 & $40,00-65,33$ & \\
\hline Lama Kerja & $\leq 5$ tahun & 53,411 & 15,10 & $33,33-80,67$ & 0,706 \\
& $>5$ tahun & 52,20 & 15,78 & $15,67-92,00$ & \\
\hline Perlakuan & Intervensi & 56,942 & 15,71 & $30,33-92,00$ & 0,002 \\
& Kontrol & 47,78 & 13,91 & $15,67-80,33$ & \\
\hline
\end{tabular}

Berdasarkan tabel 4 menjelaskan bahwa tidak ada hubungan yang signifikan antara usia, pendidikan formal, pendidikan non formal, tempat kerja dan lama kerja dengan kemampuan interpretasi EKG normal dan aritmia(nilai $p>0,05$ ). Terdapat hubungan yang signifikan antara perlakuan dengan kemampuan interpretasi EKG normal dan aritmia (nilai $\mathrm{p}<0,05$ ).

Tabel. 5

Model Awal Multivariat Juli $2020(n=111)$

\begin{tabular}{lcccc}
\hline \multirow{2}{*}{ Variabel } & \multicolumn{4}{c}{ Model Awal } \\
\cline { 2 - 5 } & Koefisien B & SE & $T$ & P-Value \\
\hline Konstanta & 77,996 & 7,828 & 9,964 & 0,000 \\
\hline Tempat Kerja & $-4,511$ & 2,464 & $-1,381$ & 0,070 \\
\hline Perlakuan Penelitian & $-8,763$ & 2,896 & $-3,123$ & 0,002 \\
\hline
\end{tabular}

Berdasarkan tabel 5 menjelaskan bahwa variabel tempat kerja memiliki nilai $p$ value $>0,05$, sehingga harus dikeluarkan dari model. Sementara variable perlakuan penelitian memiliki nilai $p$-value $<0,05$ maka tetap dipertahankan dalam model.

Tabel. 6

Model Akhir Multivariat $2020(n=111)$

\begin{tabular}{lcccc}
\hline \multirow{2}{*}{ Variabel } & \multicolumn{4}{c}{ Model Akhir } \\
\cline { 2 - 5 } & Koefisien B & SE & $T$ & p-value \\
\hline Konstanta & 66,099 & 4,411 & 14,986 & 0,000 \\
Perlakuan Penelitian & $-9,156$ & 2,828 & $-3,238$ & 0,002 \\
\hline
\end{tabular}

Berdasarkan tabel 6 menjelaskan bahwa variabel perlakuan memberikan kontribusi terhadap kemampuan perawat dalam intepretasi EKG normal dan aritmia dengan nilai $\mathrm{p}=0,002$ namun pola linier negative (kemampuan perawat $=66,099-9,156$ (perlakuan).

\section{PEMBAHASAN}

\section{Kemampuan Perawat dalam Interpretasi EKG Normal dan Aritmia}

Kemampuan interpretasi EKG normal dan aritmia sebesar 66,099. Semakin banyak perlakuan penelitian maka kemampuan perawat dalam interpretasi EKG normal dan aritmia akan semakin menurun.

Input pada penelitian ini adalah perawat dari RS Tarakan Jakarta yang memenuhi kriteria inklusi. Sedangkan proses dalam penelitian ini adalah workshop interpretasi EKG secara virtual, adapun faktor-faktor yang mempengaruhi proses belajar yang pertama adalah pendidikan formal. 
Karakteristik responden pada kelompok intervensi dan kelompok kontrol lebih dari separuh responden berpendidikan D3 Keperawatan (70,7\% dan 56,6\%). Hubungan pendidikan dengan kemampuan interpretasi EKG normal dan aritmia, didapatkan hasil tidak ada hubungan yang signifikan antara pendidikan dengan kemampuan perawat dalam interpretasi EKG normal dan aritmia dengan nilai p-value 0,849 .

Terdapat perbedaan dengan hasil penelitian yang dilakukan oleh Marlisa \& Pratiwi (2019) dengan mayoritas pendidikan responden adalah S1, menyatakan bahwa semakin tinggi tingkat pendidikan seseorang maka akan semakin baik pula tingkat pengetahuannya.Begitu juga hasil penelitian (Is1k et al., 2020). Menyatakan bahwa ada perbedaan yang signifikan antara skor pretes perawat yang memiliki pendidikan pascasarjana tentang interpretasi EKG dan yang tidak $(\mathrm{p}=0,002)$.

Karakteristik responden pada kedua kelompok sebagian besar sudah pernah mengikuti pendidikan non formal(100\%), tetapi workshop EKG hanya sebagian kecil baik pada kelompok intervensi maupun pada kelompok kontrol (3,4\% dan 0,0\%), begitu juga seminar EKG hanya diikuti oleh sebagian kecil baik pada kelompok intervensi maupun kelompok kontrol $(5,2 \%$ dan $1,9 \%)$ dan hasil uji bivariat tidak ada hubungan yang signifikan antara pendidikan non formal dengan kemampuan perawat dalam interpretasi EKG normal dan aritmia dengan nilai p-value 0,499. Ini sejalan dengan penelitian yang dilakukan oleh Marlisa \& Pratiwi (2019) didapatkan hanya sebagian kecil perawat di ruang Intensive Cardiac Care Unit (ICCU) RSUD Dr.Pirngadi Medan, yaitu sebesar $23 \%$.

Faktor yang ketiga yang mempengruhi proses belajar pada penelitian ini adalah tempat kerja, dimana lebih dari separuh responden pada penelitian ini berasal dari rawat inap baik pada kelompok intervensi maupun pada kelompok kontrol $(58,6 \%$ dan $66,0 \%$ ). Hubungan tempat kerja dengan kemampuan interpretasi EKG normal dan aritmia, didapatkan hasil tidak ada hubungan yang signifikan antara tempat kerja dengan kemampuan perawat dalam interpretasi EKG normal dan aritmia dengan nilai $p$-value 0,073. Ini dikarenakan responden yang berasal dari ruang critical care sudah banyak yang mengikuti pelatihan kardiologi dasar atau pelatihan ICU, dimana kedua pelatihan di atas sebagai kriteria eksklusi pada penelitian ini.

Faktor yang keempat yang mempengaruhi proses belajar pada penelitian ini adalah lama kerja, dimana karakteristik responden berdasarkan lama kerja pada kelompok intervensi sebagian besar $>5$ tahun $(80 \%)$. Sedangkan pada kelompok kontrol lebih dari separuh responden memiliki lama kerja $>5$ tahun $(56,6 \%)$. Hubungan lama kerja dengan kemampuan interpretasi EKG normal dan aritmia, didapatkan hasil tidak ada hubungan yang signifikan antara lama kerja dengan kemampuan perawat dalam interpretasi EKG normal dan aritmia dengan nilai p-value 0,706. Hasil ini berbeda dengan penelitian Marlisa \& Pratiwi (2019) yang menyatakan bahwa mayoritas perawat memiliki pengetahuan baik berdasarkan masa kerja $>10$ tahun sebanyak 4 responden $(31 \%)$.

Faktor lain yang tidak diteliti pada penelitian ini tetapi akan mempengaruhi kemampuan perawat dalam interpretasi EKG normal dan aritmia yaitu faktor lingkungan. Sedangkan faktor lingkungan kedua adalah lingkungan sosial, yaitu manusia dengan segala interaksinya serta representasinya seperti keramaian atau kegaduhan, lalu lintas, pasar dan sebagainya. Pada penelitian ini lokasi responden saat mengikuti workshop interpretasi EKG normal dan aritmia beranekaragam baik untuk kelompok intervensi maupun kelompok kontrol, ada yang mengikuti di ruang diklat RS Tarakan, di rumah masing-masing, di tempat kerja dan ada juga yang mengikuti 
kegiatan sambil melakukan aktivitas di tempat kerja. Sedangkan untuk pemateri dan host berada di rumah masing-masing dengan dilengkapi perangkat komputer.

Output pada penelitian ini adalah kemampuan interpretasi EKG normal dan aritmia, dari hasil uji bivariat terdapat perbedaan signifikan rerata nilai kemampuan perawat dalam intepretasi EKG normal dan aritmia sebelum dan sesuah perlakuan baik pada kelompok intervensi maupun kelompok kontrol ( $p$-value 0,007 dan 0,002). Namun kelompok intervensi memiliki selisih nilai rerata lebih besar dari kelompok kontrol.

Perlakuan pada kelompok intervesi menggunakan metode angka 3. Metode angka 3 adalah metode pembelajaran yang aktif, inovatif, kreatif, efektif dan menyenangkan dalam mempelajari interpretasi EKG normal dan aritmia, adapun inovatif dan kreatifitas metode angka 3 adalah angka 3 diambil dari banyaknya huruf dari kata EKG yang terdiri dari huruf $\mathrm{E}$ bermakna elektro, huruf $\mathrm{K}$ bermakna kardio dan huruf $\mathrm{G}$ bermakna grafik. Hal ini didesain agar peserta mudah dalam memahami dasar-dasar EKG dan dalam pengembangan tiap-tiap tema terdiri dari 3 subtema seperti untuk memahami huruf E yang bermakna elektro ada 3 hal yang harus dipahami yaitu sifat listrik jantung, sistem konduksi dan elektrofisiologi. Huruf $\mathrm{K}$ yang bermakna kardio juga memiliki 3 subtema yaitu anatomi jantung, arteri koroner dan sistem sirkulasi. Begitu juga huruf $\mathrm{G}$ yang bermakna grafik terdiri dari 3 subtema yaitu kertas EKG, sadapan EKG dan EKG normal dan dalam penjelasan tiap sub tema juga dibagi menjadi 3 bagian.

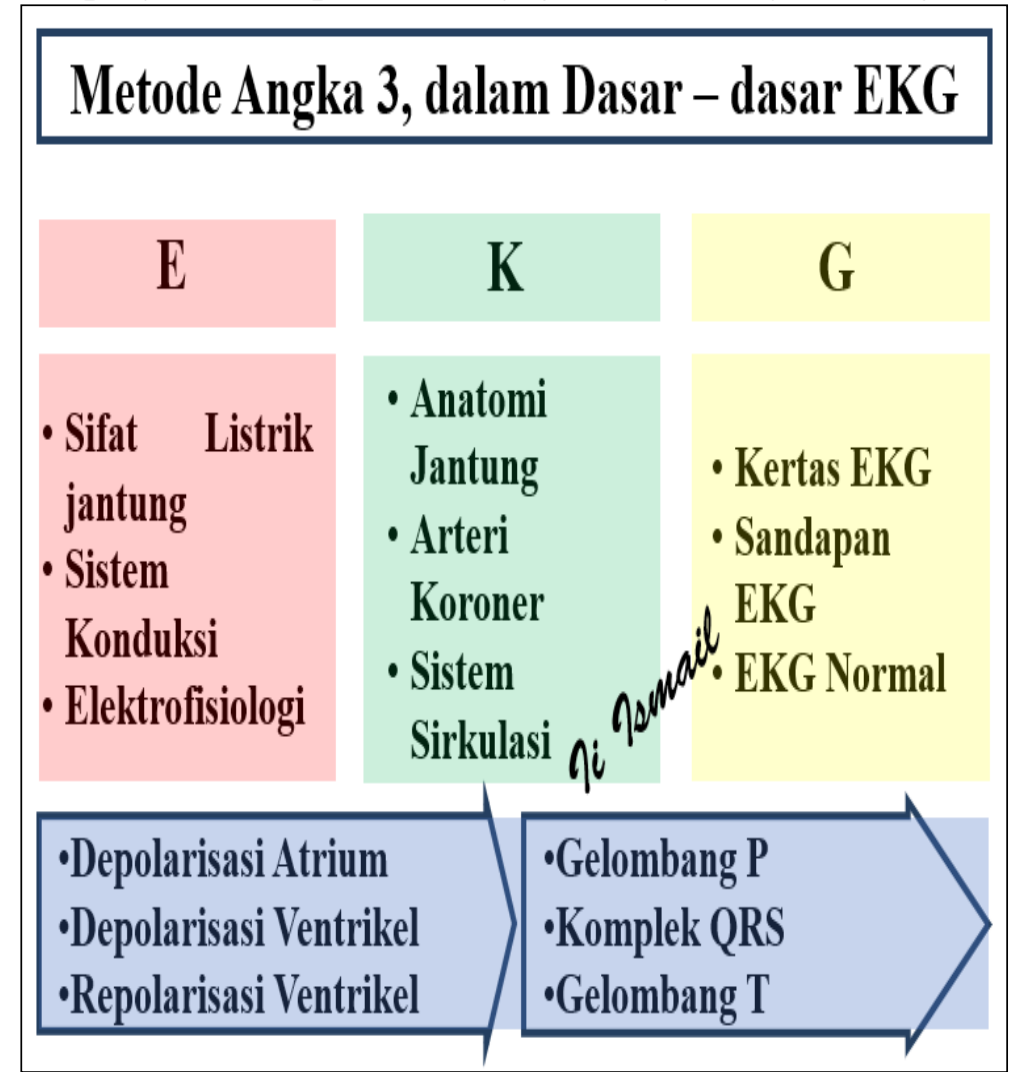

Sedangkan yang dimaksud efektif dan menyenangkan dalam metode angka 3 adalah peserta dimudahkan dalam memahami karakteristik grafik EKG, grafik EKG terdiri dari gelombang $\mathrm{P}$, komplek QRS dan gelombang $\mathrm{T}$, agar grafik EKG ini mudah dipahami dan menyenangkan, dalam memahaminya maka dalam metode angka 3 dijelaskan bahwa grafik EKG ada 3 yaitu gelombang P diilustrasikan suami, komplek QRS diilustrasikan istri dan gelombang $\mathrm{T}$ diilustrasikan anak, jadi jika gelombang $\mathrm{P}$ 
diikuti komplek QRS disebut sinus, sama halnya jika suami diikat istri dan anak disebut keluarga.

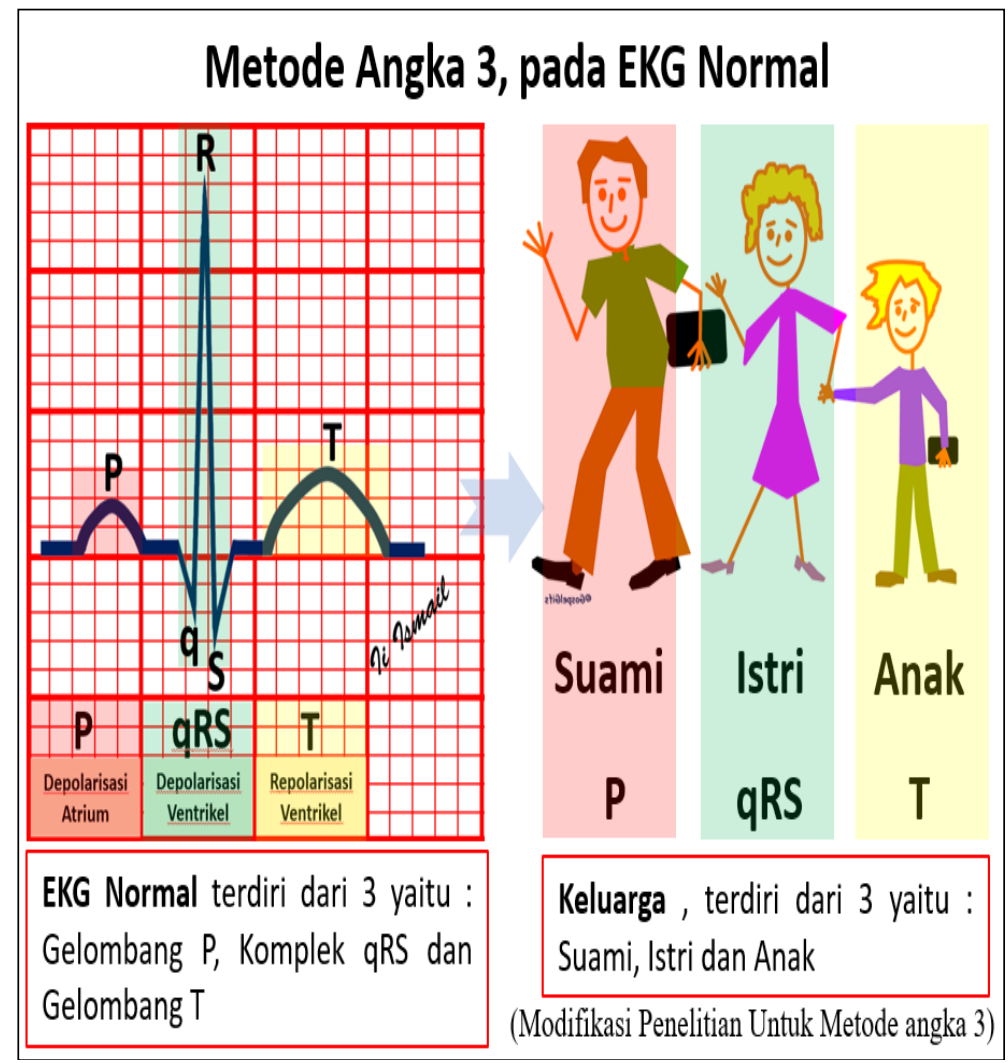

Inovasi dan kreatifitas metode angka 3 dalam interpretasi EKG normal dan aritmia dimulai dari mempelajari interpretasi EKG dasar yang terdiri dari 3 hal yaitu standar perekaman EKG, menilai irama EKG apakah teratur atau tidak teratur dan menghitung laju jantung. Setelah peserta mampu melakukan interpretasi EKG dasar maka peserta diajarkan metode angka 3 dalam interpretasi EKG normal dan aritmia, dimana metode angka 3 dalam interpretasi EKG normal dan aritmia merupakan hasil modifikasi dari metode Cardiac Rhythm Identification For Simple People (CRISP), metode ini merupakan sebuah algoritma yang dirancang untuk membantu perawat dalam menginterpretasikan EKG dengan cepat yang terdiri dari 3 langkah, yang pertama mengidentifikasi komplek QRS, kedua mengidentifikasi gelombang P dan yang ketiga mengidentifikasi kembali komplek QRS apakah sempit atau lebar.

Modifikasi dengan metode angka 3 didasari oleh adanya 3 langkah dalam belajar interpretasi EKG normal dan aritmia didesain menggunakan 3 tahapan yaitu tahap pertama analisa adakah komplek QRS, langkah kedua analisa apakah komplek QRS sempit atau lebar dan langkah ketiga analisa gelombang P. Perbedaan metode CRISP dan metode angka 3 terletak di langkah ke 2 dimana pada metode CRIPS analias gelombang P, sedangkan pada metode angka 3 menganalisa komplek QRS lebar atau sempit dan langkah ke 3, dimana pada metode CRIPS analisa komplek QRS sempit atau lebar sedangkan pada metode angka 3 dengan menganalisa apakah gelombang $\mathrm{P}$ ada atau tidak. Agar peserta mudah memahami dibuatkan algoritma interpretasi EKG normal dan aritmia dengan metode angka 3 yaitu dengan menggunakan 3 langkah, seperti yang sudah dijelaskan di bawah. 


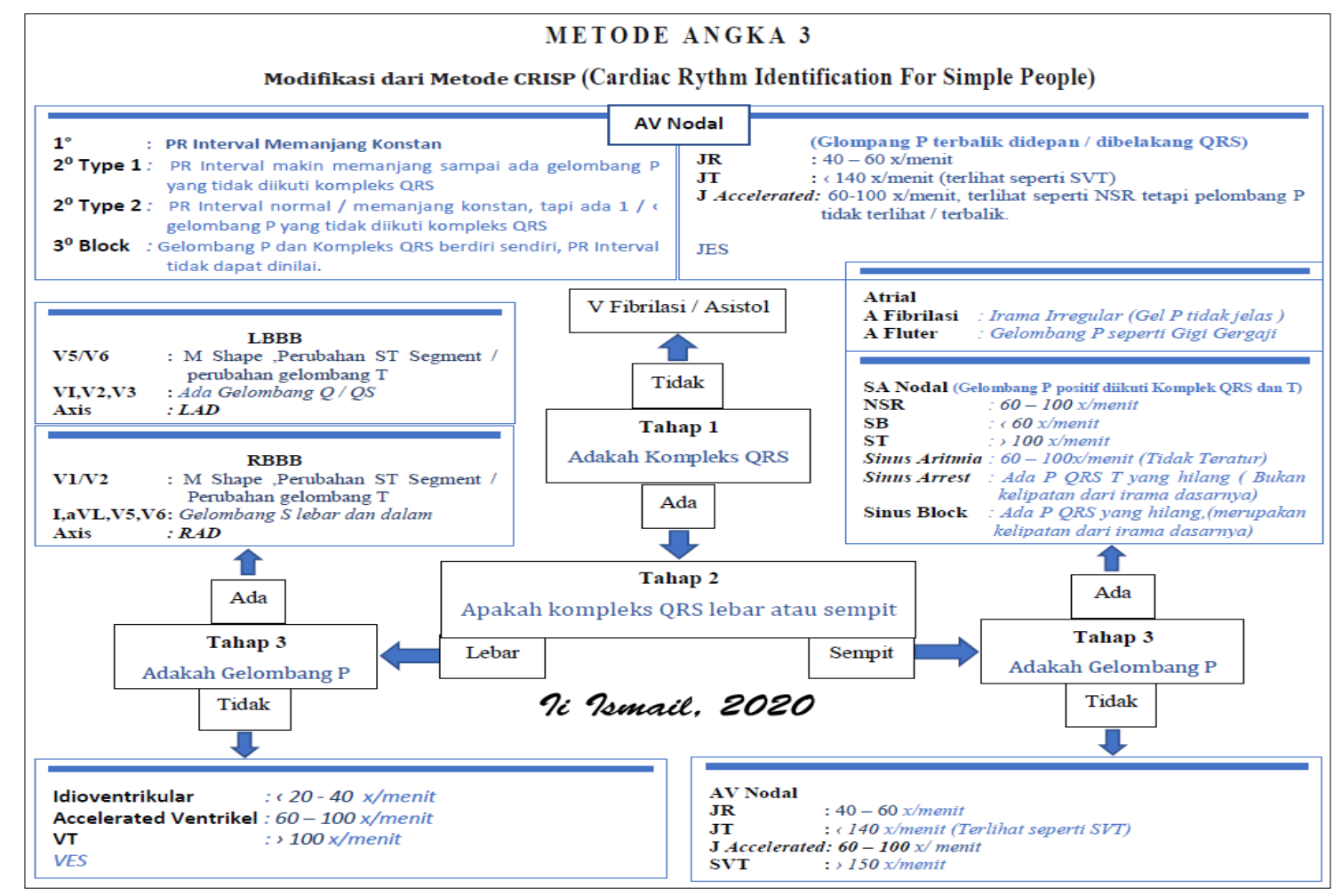

Yang dimaksud aktif dalam metode angka 3 yaitu peserta diberikan kesempatan untuk bertanya dan mencoba menganalisa gelombang EKG sampai latihan interpretasi EKG normal dan aritmia.

Sedangkan Interpretasi EKG dengan modul Ikatan Ners Kardiovaskuler Indonesia (INKAVIN) dimana pada workshop interpretasi EKG dipelajari tentang konsep dasar EKG yang meliputi anatomi dan fisiologi jantung, konsep dasar EKG dan pembelajaran aritmia yang dibagi menjadi dua yaitu pertama aritmia karena gangguan pembentukan yang terdiri dari EKG sinus meliputi (sinus takikardi, sinus bradikardi, sinus aritmia dan sinus arrest), EKG atrial meliputi (atrial takikardi, atrial fibrilasi, atrial flutter). EKG junctional meliputi (junctional ritme, junctional takikardi dan junctional akselerasi), EKG supraventrikel takikardi, EKG ventrikel meliputi (idioventricular ritme, akselerasi idioventricular ritme, ventrikel takikardi dan ventrikel fibrilasi). Kedua aritmia karena gangguan hantaran yang terdiri dari EKG sinus blok, AV block derajat 1, AV block derajat 2 tipe I, AV Block derajat 2 tipe II, total AV Block, RBBB dan LBBB. disertai latihan interpretasi EKG normal dan aritmia.

Interpretasi EKG dengan modul INKAVIN dapat meningkatkan kemampuan perawat dalam interpretasi EKG normal dan aritmia, dikarenakan INKAVIN selalu melakukan pembaharuan dalam menyelenggarakan pelatihan interpretasi EKG untuk perawat dan sudah memiliki modul pelatihan interpretasi EKG untuk perawat. Bahkan metode angka 3 juga merupakan pengembangan dari modul INKAVIN.

\section{SIMPULAN}

Terdapat perbedaan yang signifikan rerata nilai perawat dalam interpretasi EKG normal dan aritmia baik pada kelompok intervensi maupun kontrol. Namun kelompok intervensi memiliki selisih nilai rata-rata lebih besar dari kelompok kontrol. Perlakuan 
secara simultan berhubungan dengan kemampuan perawat dalam interpretasi EKG normal dan aritmia dengan pola linier negatif.

\section{SARAN}

Metode angka 3 dapat dijadikan referensi untuk meningkatkan kompetensi perawat dalam melakukan interpretasi EKG normal dan aritmia dan dapat dijadikan acuan juga bahan pertimbangan penelitian selanjutnya sehingga dapat digunakan sebagai dasar pengembangan metode angka 3 pada kasus yang lebih komplek, misalkan pengembangan metode angka 3 pada EKG Acute Coronary Syndrome (ACS). Metode angka 3 dapat dijadikan salah satu metode dalam mempelajari interpretasi EKG normal dan aritmia di lingkungan pendidikan keperawatan baik secara formal maupun non formal. Untuk lebih meningkatkan efektivitas metode angka 3 ini diperlukan penelitian lanjutan mengenai interpretasi EKG normal dan aritmia dengan pelaksanaan di dalam kelas dan dengan memperhatikan lingkup kerja responden.

\section{DAFTAR PUSTAKA}

Isık, G. Ç., Şafak, T., Tandoğan, M., \& Çevik, Y. (2020). Effectiveness of the CRISP Method on the Primary Cardiac Arrhythmia Interpretation Accuracy of Nurses. Journal of Continuing Education in Nursing, 51(12), 574-580. https://doi.org/10.3928/00220124-20201113-08

Marlisa, M., \& Pratiwi, D. N. (2019). Gambaran Pengetahuan Perawat tentang Interpretasi EKG pada Pasien Aritmia di Ruang ICCU Rsud Dr Pirngadi Medan. Jurnal Ilmiah Panmed, 13(3), 195-200. http://ojs.poltekkesmedan.ac.id/pannmed/article/download/590/427

McGrath, A., \& Sampson, M. (2018). Electrocardiograms: A Guide to Rhythm Recognition for Emergency Nurses. In Emergency Nurse (Vol. 26, Issue 1, pp. 23-30). https://doi.org/10.7748/en.2018.e1767

Sila, N. A. (2018). Pengembangan Aplikasi Algoritma Ekg Berbasis Sistem Android dalam Meningkatkan Kemampuan dan Kecepatan Perawat Melakukan Interpretasi Ekg Dasar di Rumah Sakit Universitas Airlangga Surabaya. Universitas Airlangga Surabaya, 91(5), 43. http://dx.doi.org/10.1016/j

Wibawa, H. ari. (2019). Perbedaan Pengaruh Metode Belajar Crisp dan Modified Disbi terhadap Kemampuan Perawat Melakukan Interpretasi EKG Strip di RSUD Sleman. In Repository Universitas Jenderal Soedirman. http://repository.unsoed.ac.id/2071/ 